\title{
Synchrophasor Based Novel Fault Location Algorithm for Three- Terminal Transmission Line
}

\author{
${ }^{\text {*1 } M a i t r e y e e ~ S o n t a k k e, ~}{ }^{2}$ Trupti Hinge, ${ }^{3}$ Sanjay Dambhare \\ ${ }_{1,3}$ Dept. of Electrical Engineering, College of Engineering, Pune, India \\ ${ }^{2}$ Dept. of Electrical Engineering, Rajarshi Shahu College of Engineering, Pune, India \\ Email:maitreyees21@gmail.com,truptihinge1@gmail.com,sanjay.dambhare@gmail.com
}

\section{Received: 15th October 2019, Accepted: 31st January 2020, Published: 30th April 2020}

\begin{abstract}
A fault detection and location algorithm on three-terminal transmission line is proposed. Vast literature on fault location shows that to simplify the analysis, line charging currents are often ignored. To improve the accuracy of fault location, synchronized current and voltage measurements from three ends of the three-terminal line are utilized to detect and locate distance to fault while considering the line charging currents. The method first detects the zone at which the fault has occurred and then locates it from the respective line ends. Since threeterminal lines provide solutions for connecting existing system to the grid, facilitating bulk transfer of power, thus the fault detection and location on the same is important to maintain reliability and security of the system. Performance of the proposed algorithm is tested for various fault types, fault locations, fault resistances and fault inception angles. The 200-kV system is simulated in ATP/EMTP; however, the algorithm is developed in MATLAB. The extensive simulation studies demonstrate accuracy of the proposed scheme.
\end{abstract}

\section{Keywords}

Fault Detection, Fault Location, Synchronized Measurements, Synchrophasor, Three Terminal Line.

\section{Introduction}

In power systems, the distribution and transmission links ensure the continuity of power from the generation end to the other. In case of faults, it is very important to clear them at the earliest to restore the interrupted power supply. Thus, to speed up the restoration of power, fault-location techniques are vital from the view of economic reliability and quality of power being fed. Three-terminal and tapped lines reasonably provide temporary solutions for connecting areas that are closer to an existing transmission line to grid without the need for constructing a new substation, until the need is actually justifiable. Since, measurements are not available at the junction of the three-terminal line, fault location should be accompanied by detection of the zone at fault first by using synchrophasor based technology. With the invention and thereby increasing usage of Phasor Measurement Units (PMUs), Global Positioning System (G.P.S.) and fiber optic communication, measurements from ends of the line can be conveniently utilized to locate distance to fault.

In the past, many algorithms were developed on fault location, most of which are related to two-terminal lines fault location, some amongst them made use of unsynchronized voltage and current data from the two- end terminals [1]-[2] while others utilized synchronized data for locating distance to fault [3]-[4]. Also, techniques have been proposed for fault location on three-terminal and tapped lines. Most of the above algorithms neglect line charging currents. Reference [5] first frames an optimization problem to find the line parameters and then utilizes the same in detecting and locating the distance to fault by making use of synchronized transient measurements. Protection of three-terminal transmission lines against power swing related issues is dealt with in [6] using voltage calculated at tee point utilizing positive sequence synchronized current and voltage measurements.

Reference [7] also makes use of synchronized measurements to locate faults on in-service and out-service line branch of the three-terminal line. Location of faults using dynamic parameters of three-terminal lines utilizing Newton's iterative method is achieved under dynamic fault conditions by first identifying section at fault [8]. Direct underreaching transfer trip (DUTT) scheme makes use of a system of communication between the line ends by taking into account the pre-fault measurements at the ends [9]. Ensuring overlapping between settings of zone 1 is essential for reliable operation of DUTT scheme. Time instances of arrival of fault-generated traveling waves are noted to locate distance to fault for both three terminal single-and double-circuit transmission lines [10].

Current transformer errors introduced in estimating the location to fault are eliminated by making use of only the negative sequence component of voltages to detect and estimate the distance to fault in three- terminal line [11]. Indices based on graph theory are first developed for two- and three-terminal transmission lines using the 
data window for optimal calculation which is then extended to multi-terminal lines to detect and locate distance to fault [12]. Another method estimating the distance to fault makes use of traveling waves for hybrid threeterminal systems which include onshore overhead line as well as offshore cables making use of discrete wavelet transformation [13]. Reference [14] also makes use of wavelet transform but is different from [13] in a way that this method proposes combined fault locator for three- terminal lines and is based on high and low frequency components of the signals that originate from fault conditions in the system.

Fault location on transmission line is first facilitated by optimally placing PMUs to optimize the installation cost but making sure that every bus in the network is observable [15]. Fault location in three-terminal line is also facilitated by wavelet transform and is validated for inclusion of series compensation, mutually coupled line section for various values of fault resistances [16]. In contrast to [11], reference [17] makes use of three- phase currents from all line ends and three-phase voltage from the end at which fault locator is installed with the aim of developing a fault locating algorithm for applications with current differential relays. Fault location using optimal placement of PMUs in existing networks involves selection of fault-side at first and then estimating the distance to fault [18].

The algorithm is used to locate faults for two-terminal line in [19]. This paper computes the distance to fault using positive sequence components of voltages and currents of the three-terminal line by appropriately compensating charging currents as well. The time synchronized voltage and current measurements are obtained from the ends of the three-terminal line. By using these measurements, the zone at which fault has occurred is first detected by using voltage magnitude method and is confirmed by current phase comparison method [20], followed by estimating the distance to fault using sequence component theory. Simulation studies include all types of asymmetrical and symmetrical faults with varying fault resistances, fault inception angles, results for which prove reliability of the proposed method.

\section{Method}

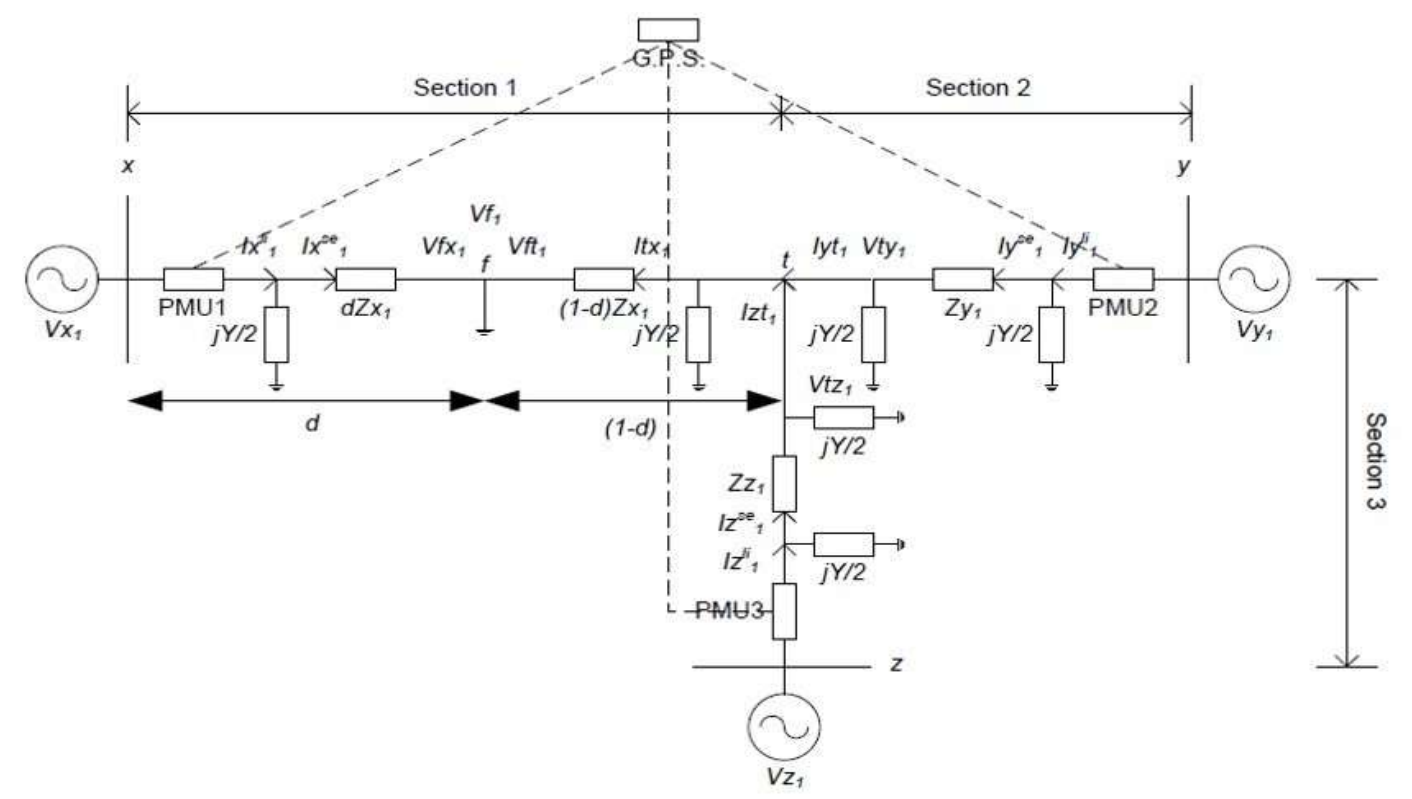

Fig. 1: Three-Terminal Line Positive Sequence Representation with Fault on First Section

Let us consider a three-terminal transmission line with PMUs as shown in Fig.1 represented in sequence domain. Bus voltages and line currents are represented with appropriate notations. PMUs, as shown are installed at the three ends of the three-terminal line for voltage and current measurements. The symmetrical components theory can be utilized since fully transposed lines are considered without the need to make any simplifying assumptions. Thus,

$I_{0}=(1 / 3)\left(I_{a}+I_{b}+I_{c}\right) ; I_{1}=(1 / 3)\left(I_{a}+a I_{b}+a^{2} I_{c}\right) ; I_{2}=(1 / 3)\left(I_{a}+a^{2} I_{b}+a I_{c}\right)$

$\mathrm{V}_{0}=(1 / 3)\left(\mathrm{V}_{\mathrm{a}}+\mathrm{V}_{\mathrm{b}}+\mathrm{V}_{\mathrm{c}}\right) ; \mathrm{V}_{1}=(1 / 3)\left(\mathrm{V}_{\mathrm{a}}+\mathrm{a} \mathrm{V}_{\mathrm{b}}+\mathrm{a}^{2} \mathrm{~V}_{\mathrm{c}}\right) ; \mathrm{V}_{2}=(1 / 3)\left(\mathrm{V}_{\mathrm{a}}+\mathrm{a}^{2} \mathrm{~V}_{\mathrm{b}}+\mathrm{a} \mathrm{V}_{\mathrm{c}}\right)$

where, $V_{a}, V_{b}, V_{c}$ are phase components of voltages respectively, $V_{0}, V_{1}, V_{2}$ are zero, positive and negative 
sequence components of voltages respectively, $\mathrm{I}_{\mathrm{a}}, \mathrm{I}_{\mathrm{b}}, \mathrm{I}_{\mathrm{c}}$ are phase components of currents respectively and $\mathrm{I}_{0}$, $\mathrm{I}_{1}, \mathrm{I}_{2}$ are zero, positive and negative sequence components of currents respectively.

Thus, after phasor estimation and sequence transformation, we get six positive sequence components, namely, $\mathrm{Ix}_{1}, \mathrm{Iy}_{1}, \mathrm{Iz}_{1}, \mathrm{Vx}_{1}, \mathrm{Vy}_{1}, \mathrm{Vz}_{1}$.

where, $\mathrm{Ix}_{1}, \mathrm{Iy}_{1}, \mathrm{Iz}_{1}$ are positive sequence currents from end terminals and $\mathrm{Vx}_{1}, \mathrm{Vy}_{1}, \mathrm{Vz}_{1}$ are positive sequence voltages from end terminals and $\mathrm{Zx}, \mathrm{Zy}$ and $\mathrm{Zz}$ are line impedances from sections $\mathrm{x}-\mathrm{t}, \mathrm{y}-\mathrm{t}$ and $\mathrm{z}-\mathrm{t}$ respectively, $\mathrm{Y}_{1}$ is charging current admittance and $\mathrm{Vf}$ is voltage at fault point $\mathrm{f}$,

$\mathrm{Vfx}_{1}$ and $\mathrm{Vft}_{1}$ are voltages at fault point calculated from ends $\mathrm{x}$ and $\mathrm{t}$ respectively and a is $1 \angle 120$ degrees. Assuming fault occurs only on one section at a time, from Fig. 1, fault is considered on Section 1.

From terminal $\mathrm{x}$,

$\mathrm{Ix}^{\mathrm{se}_{1}}=\mathrm{Ix}^{\mathrm{li}}{ }_{1}-\mathrm{j}\left(\mathrm{Y}_{1} / 2\right) \mathrm{Vx}_{1}$

$\mathrm{Vfx}_{1}=\mathrm{Vx}_{1}-\mathrm{dZx_{1 }} \mathrm{Ix}^{\mathrm{se}_{1}}$

From terminal y, $\mathrm{Iy}^{\mathrm{se}_{1}}=\mathrm{Iy}^{\mathrm{li}}{ }_{1}-\mathrm{j}\left(\mathrm{Y}_{1} / 2\right) \mathrm{Vy}_{1}$

$\mathrm{Vty}_{1}=\mathrm{Vy}_{1}-\mathrm{Zy}_{1} \mathrm{Iy}_{1}^{\mathrm{se}_{1}}$

$\mathrm{Iyt}_{1}=\mathrm{Iy}^{\mathrm{se}_{1}}-\mathrm{j}\left(\mathrm{Y}_{1} / 2\right) \mathrm{Vty}_{1}$

From terminal $\mathrm{z}, \mathrm{Iz}^{\mathrm{se}_{1}}=\mathrm{Iz}_{1}{ }_{1}-\mathrm{j}\left(\mathrm{Y}_{1} / 2\right) \mathrm{Vz}_{1}$

$\mathrm{Vtz}_{1}=\mathrm{Vz}_{1}-\mathrm{Zz}_{1} \mathrm{Iz}^{\mathrm{se}_{1}}$

$\mathrm{Izt}_{1}=\mathrm{Izd}_{1}-\mathrm{j}\left(\mathrm{Y}_{1} / 2\right) \mathrm{Vd}_{1}$

Thus, from equation nos. (5) and (8),

$\mathrm{Itx}_{1}=\mathrm{Iyt}_{1}+\mathrm{Izt}_{1}$

$\mathrm{Vft}_{1}=\mathrm{Vty}_{1}-(1-\mathrm{d}) \mathrm{Itx}_{1}$

To calculate voltage at fault point from the other end, either of the two ends i.e. ' $y$ ' and ' $z$ ' can be considered since none of the two are at fault. Considering voltage drop from end 'y' and equating equation nos. (2) and (10) and appropriately substituting other values, thus derived to get distance to fault 'd',

$\mathrm{d}=\mathrm{Vx}_{1}+\mathrm{Zx}_{1} \mathrm{Itx}_{1}-\mathrm{Vty}_{1} \mathrm{Zx}_{1} \mathrm{I}_{1}^{\mathrm{se}}+\mathrm{Zx}_{1} \mathrm{Itx}_{1}$

Currents $\mathrm{Ix}^{\mathrm{se}}{ }_{1}, \mathrm{Ix}^{\mathrm{li}}{ }_{1}$, Iy ${ }^{\mathrm{se}}{ }_{1}, \mathrm{Iy}^{\mathrm{li}}{ }_{1}, \mathrm{Iz}^{\mathrm{se}}{ }_{1}, \mathrm{Iz}^{\mathrm{li}}{ }_{1}, \mathrm{Itx}_{1}$, Iyt $\mathrm{It}_{1}$ and $\mathrm{Iyt}_{1}$ are appropriately shown in Fig. 1 , where, $\mathrm{I}_{\mathrm{a}}, \mathrm{I}_{\mathrm{b}}, \mathrm{I}_{\mathrm{c}}$ are phase components of currents respectively,

$\mathrm{I}_{0}, \mathrm{I}_{1}, \mathrm{I}_{2}$ are zero, positive and negative sequence components of currents respectively.

Extensive simulations are performed in ATP/EMTP to decide the voltage threshold value, $\mathrm{e}=800$. This value is used to decide the zone at which fault has occurred.

\section{Methodology}

Algorithm

Flowcharts of the proposed method is as shown in Fig. 2 and Fig. 3.

1) Input sampling frequency (fs).

2) Obtain time synchronized samples of three-phase currents and voltages of all the sections of the three- terminal line, i.e. $V_{a b c} x(t), I_{a b c} x(t), V_{a b c} y(t), I_{a b c} y(t), V_{a b c} z(t), I_{a b c} z(t)$ from buses $x, y$ and $z$ respectively. Time $t$ is indicative of the time of the newest sample whereas $a, b$ and $c$ denote the three phases.

3) Use Full Cycle Recursive DFT technique to convert thus obtained samples to phasors [21].

4) Using sequence transformation, compute the positive, negative and zero sequence components of all the three phase currents and voltages.

5) Calculate voltage at junction point ' $t$ ' from all the ends of the three-terminal line i.e. $V t_{1}, V_{1} y_{1}$ and $V_{t z}$ using three-end voltages and currents.

6) Identify the zone at fault using Voltage and Current techniques

- Voltage Magnitude Comparison Technique- If $\left|\mathrm{Vx}_{1}-\mathrm{Vty}_{1}\right|$ or $\left|\mathrm{Vx}_{1}-\mathrm{Vtz}_{1}\right|>\mathrm{e}$, fault is on section 1 else if $\mid \mathrm{Vy}_{1}$ - Vtz 1 or $\left|\mathrm{Vy}_{1}-\mathrm{Vtx}_{1}\right|>\mathrm{e}$, fault is on section 2 else if $\left|\mathrm{Vz}_{1}-\mathrm{Vtx}_{1}\right|$ or $\left|\mathrm{Vz}_{1}-\mathrm{Vty} 1\right|>\mathrm{e}$, fault is on section 3. Else go to step 2, where, $\mathrm{Vtx}_{1}, \mathrm{Vty}_{1}$ and $\mathrm{Vtz}_{1}$ are voltages calculated at the junction point ' $\mathrm{t}$ ' from the three terminals ' $\mathrm{x}$ ', ' $\mathrm{y}$ ' and ' $\mathrm{z}$ ' respectively.

- Current Phase Comparison Technique [20]- If $(\angle \mathrm{Ix})-\angle$ (Iy $+\mathrm{Iz}) \neq 180$, fault is on section 1 else if $(\angle \mathrm{Iy})-\angle$ (Iz + Ix $\neq \neq 180$, fault is on section 2 else if $(\angle \mathrm{Iz})-\angle(\mathrm{Ix}+\mathrm{Iy}) \neq 180$, fault is on section 3 . Else go to step 2 .

7) Compute and locate distance to fault by the derived formulae (11) for both symmetrical and unsymmetrical faults. 


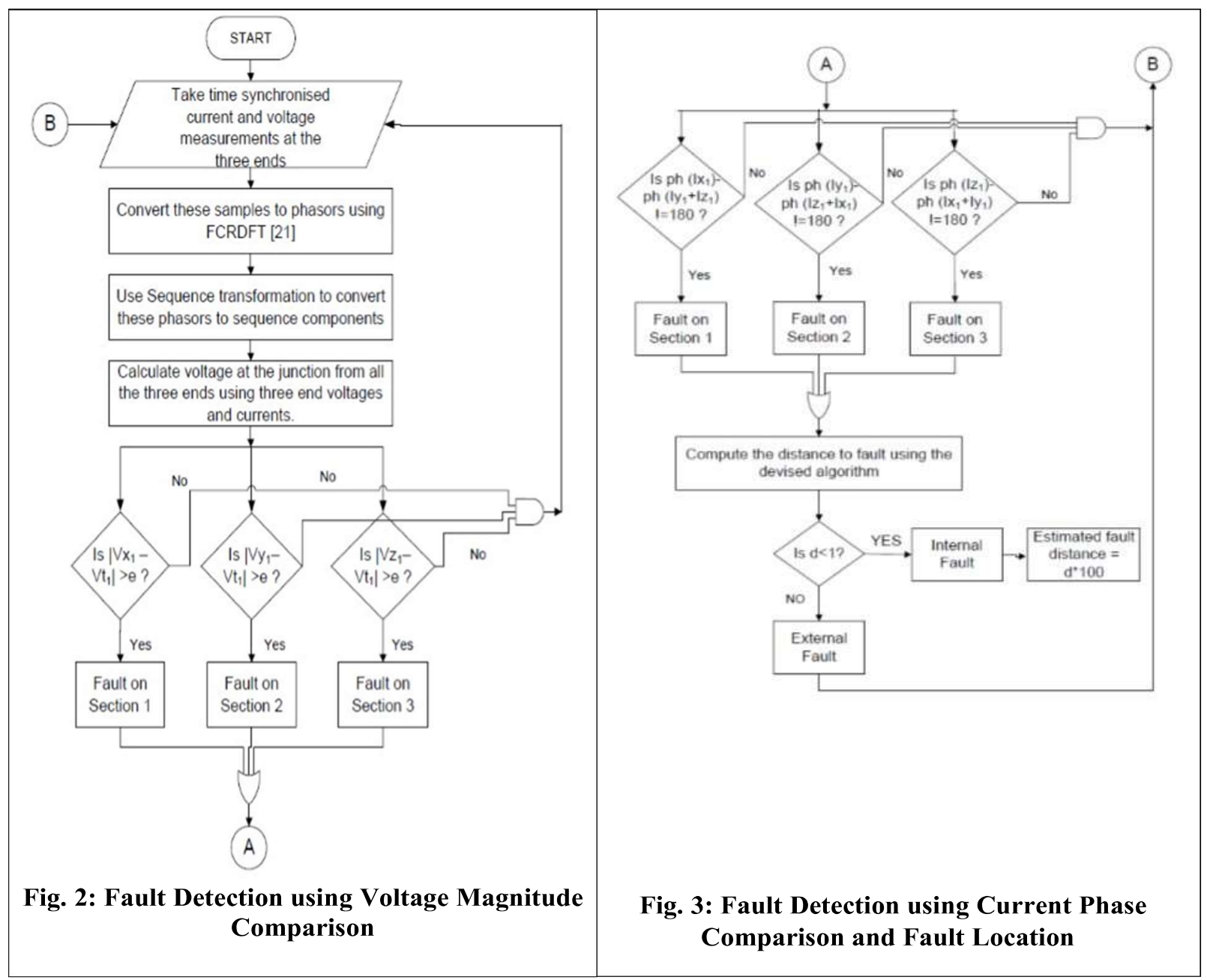

\section{Results}

The system simulated in ATP-EMTP is shown as in Appendix I. Three-terminal transmission line is modelled as shown in Fig. 4. The transmission line has equivalent- $\pi$ model with $100 \mathrm{~km}$ length. Simulations are performed in ATP/EMTP platform with $1 \mathrm{kHz}$ sampling frequency. PMUs are located at the ends of the transmission line. The algorithm implemented in MATLAB computes distance to fault from sending end of the transmission line. PMU calculates 1 phasor per cycle in a system of $50 \mathrm{~Hz}$. Various types of faults (such as LG, line to line, line to LG, three phase) with varying fault distances, fault inception angles and fault resistances have been simulated to validate the proposed algorithm on all the line sections. The results are as shown in Table I.

$$
\% \text { Error }=(\text { Actual Location - Estimated Location }) / \text { Total Line Length [19] }
$$

\section{Conclusion}

This paper proposes a novel algorithm to detect section at fault and then computes the distance to fault on threeterminal transmission line in sequence domain. The algorithm first detects the section at fault using the voltagemagnitude comparison technique and confirms the same using secure phase current comparison [20]. Distance to fault is then computed using positive sequence voltages and currents from the three-ends, appropriately compensating the line charging currents. The proposed method has good accuracy in detecting section at fault and locating the distance to fault for the tested cases.

- The algorithm detects all types of asymmetrical and symmetrical faults at varying distances and at varying fault inception angles. • The location to fault is minimally affected by inclusion of fault resistance. • The efforts of computation of distance to fault are less since the method is not iterative. $\bullet$ The algorithm is independent of modelling of impedances behind the line terminals. - No assumption on source impedance is made. 


\begin{tabular}{|c|c|c|c|c|c|c|c|c|c|c|c|c|c|}
\hline & & \multicolumn{4}{|c|}{ Section 1} & \multicolumn{4}{|c|}{ Section 2} & \multicolumn{4}{|c|}{ Section 3} \\
\hline $\begin{array}{c}\text { Fault } \\
\text { Inception } \\
\text { Angle } \\
\text { (Degrees) }\end{array}$ & & \multicolumn{2}{|c|}{45} & \multicolumn{2}{|c|}{90} & \multicolumn{2}{|c|}{45} & \multicolumn{2}{|c|}{90} & \multicolumn{2}{|c|}{45} & \multicolumn{2}{|c|}{90} \\
\hline $\begin{array}{c}\text { Fault } \\
\text { Resistance } \\
(\mathrm{Ohm})\end{array}$ & & 50 & 100 & 50 & 100 & 50 & 100 & 50 & 100 & 50 & 100 & 50 & 100 \\
\hline $\begin{array}{l}\text { Fault } \\
\text { Type }\end{array}$ & $\begin{array}{c}\text { Fault } \\
\text { Distance } \\
(\%)\end{array}$ & & & & & & & & & & & & \\
\hline \multirow[t]{3}{*}{ LG } & 10 & 0.06 & 0.11 & 0.09 & 0.04 & 0.08 & 0.05 & 0.06 & 0.1 & 0.068 & 0.07 & 0.06 & 0.08 \\
\hline & 50 & 0.06 & 0.08 & 0.1 & 0.15 & 0.15 & 0.08 & 0.09 & 0.12 & 0.06 & 0.08 & 0.07 & 0.07 \\
\hline & 90 & 0.07 & 0.05 & 0.07 & 0.065 & 0.06 & 0.07 & 0.08 & 0.05 & 0.065 & 0.05 & 0.03 & 0.06 \\
\hline \multirow[t]{3}{*}{$\overline{\mathrm{LL}}$} & 10 & 0.12 & 0.09 & 0.06 & 0.08 & 0.05 & 0.08 & 0.09 & 0.16 & 0.04 & 0.08 & 0.07 & 0.09 \\
\hline & 50 & 0.09 & 0.045 & 0.05 & 0.06 & 0.2 & 0.03 & 0.18 & 0.05 & 0.09 & 0.1 & 0.035 & 0.15 \\
\hline & 90 & 0.1 & 0.09 & 0.2 & 0.15 & 0.08 & 0.07 & 0.2 & 0.12 & 0.08 & 0.065 & 0.1 & 0.23 \\
\hline \multirow[t]{3}{*}{ LLG } & 10 & 0.05 & 0.08 & 0.12 & 0.1 & 0.09 & 0.1 & 0.065 & 0.05 & 0.12 & 0.055 & 0.05 & 0.08 \\
\hline & 50 & 0.09 & 0.05 & 0.07 & 0.2 & 0.06 & 0.045 & 0.035 & 0.07 & 0.06 & 0.1 & 0.07 & 0.2 \\
\hline & 90 & 0.08 & 0.09 & 0.16 & 0.2 & 0.3 & 0.15 & 0.08 & 0.17 & 0.2 & 0.08 & 0.05 & 0.22 \\
\hline \multirow[t]{3}{*}{3 PHASE } & 10 & 0.27 & 0.13 & 0.16 & 0.08 & 0.23 & 0.13 & 0.16 & 0.08 & 0.16 & 0.07 & 0.23 & 0.25 \\
\hline & 50 & 0.08 & 0.17 & 0.07 & 0.23 & 0.13 & 0.2 & 0.09 & 0.08 & 0.06 & 0.12 & 0.08 & 0.09 \\
\hline & 90 & 0.2 & 0.18 & 0.08 & 0.08 & 0.1 & 0.25 & 0.18 & 0.07 & 0.23 & 0.15 & 0.25 & 0.1 \\
\hline
\end{tabular}

Table 1: Performance of Proposed Algorithm for Varying Fault Types, Fault Locations and Fault Inception Angles

\section{Appendix}

The simulated system is referred from [5] with system as in Fig. 4 and parameters as in Table 2.

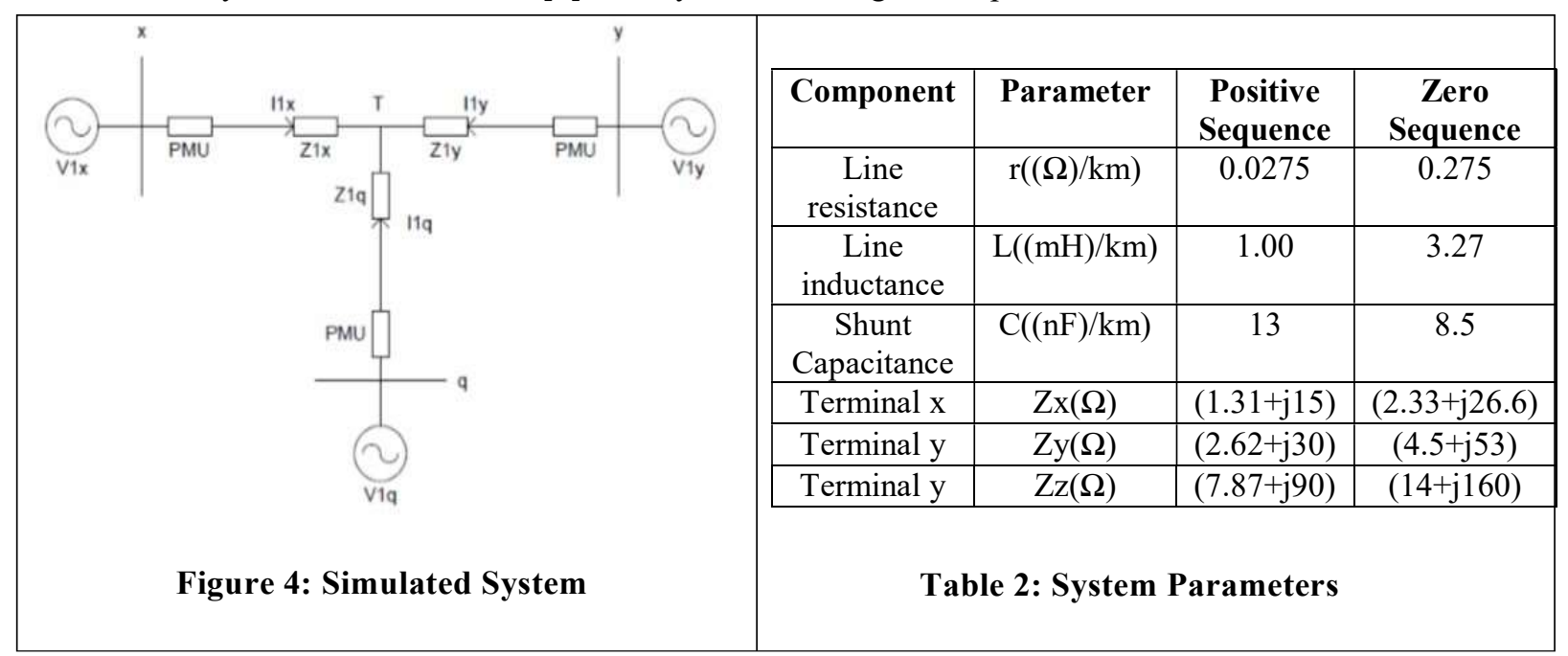

Phase angle of EMF of terminal $\mathrm{x}=0$ degree.

Phase angle of EMF of terminal $y=-20$ degrees.

Phase angle of EMF of terminal $z=-30$ degrees. 


\section{References}

[1] F. Lopes, K. Silva, F. Costa, W. Neves, and D. Fernandes, "Real-time Traveling-wave-based Fault Location Using Two-Terminal Unsynchronized Data," IEEE Transactions on Power Delivery, vol. 30, no. 3, pp. 1067-1076, 2014.

[2] F. Poutine-Ebrahimi and M. Ghazizadeh-Ahsaee, "Accurate and Comprehensive Fault Location Algorithm for Two-Terminal Transmission Lines,” IET Generation, Transmission \& Distribution, vol. 12, no. 19, pp. 43344340, 2018.

[3] F. V. Lopes and E. J. Leite, "Traveling wave-based solutions for transmission line two-terminal data time synchronisation," IEEE Transactions on Power Delivery, vol. 33, no. 6, pp. 3240-3241, 2018.

[4] M. Davoudi, J. Sadeh, and E. Kamyab, "Parameter-free Fault Location for Transmission Lines Based on Optimization," IET Generation, Transmission \& Distribution, vol. 9, no. 11, pp. 1061-1068, 2015.

[5] M. Davoudi, J. Sadeh, and E. Kamyab, “Transient-Based Fault Location on Three-Terminal and Tapped Transmission Lines not Requiring Line Parameters," IEEE Transactions on Power Delivery, vol. 33, no. 1, pp. 179-188, 2017.

[6] P. K. Nayak, A. K. Pradhan, and P. Bajpai, "A Three-Terminal Line Protection Scheme Immune to Power Swing," IEEE Transactions on Power Delivery, vol. 31, no. 3, pp. 999-1006, 2015.

[7] Y.-J. Lee, C.-H. Chao, T.-C. Lin, and C.-W. Liu, "A synchrophasor based fault location method for threeterminal hybrid transmission lines with one off-service line branch," IEEE Transactions on Power Delivery, vol. 33, no. 6, pp. 3249-3251, 2018.

[8] Z. Y. He, X. P. Li, W. He, Y. P. Liu, S. Zhang, R. K. Mai, and Q. Q. Qian, "Dynamic Fault Locator for Three-Terminal Transmission Lines for Phasor Measurement Units," IET Generation, Transmission \& Distribution, vol. 7, no. 2, pp. 183-191, 2013.

[9] S. Sarangi and A. K. Pradhan, "Adaptive direct under-reaching transfer trip protection scheme for the three- terminal line," IEEE Transactions on Power Delivery, vol. 30, no. 6, pp. 2383-2391, 2015.

[10] A. Ahmadimanesh and S. M. Shahrtash, "Time-Time-Transform-based Fault Location Algorithm for Three-Terminal Transmission Lines," IET Generation, Transmission \& Distribution, vol. 7, no. 5, pp. 464-473, 2013.

[11] B. Mahamedi, M. Sanaye-Pasand, S. Azizi, and J. G. Zhu, "Unsynchronised Fault-Location Technique for Three-Terminal Lines," IET Generation, Transmission \& Distribution, vol. 9, no. 15, pp. 2099-2107, 2015.

[12] Y.-J. Lee, T.-C. Lin, and C.-W. Liu, "Multi-terminal nonhomogeneous transmission line fault location utilizing synchronized data," IEEE Transactions on Power Delivery, vol. 34, no. 3, pp. 1030-1038, 2019.

[13] R. J. Hamidi and H. Livani, "Traveling-wave-based Fault-Location Algorithm for Hybrid Multi-terminal Circuits," IEEE Transactions on Power Delivery, vol. 32, no. 1, pp. 135-144, 2016.

[14] M. da Silva, D. V. Coury, M. Oleskovicz, and E. Segatto, "Combined Solution for Fault Location in ThreeTerminal Lines based on Wavelet Transforms," IET Generation, Transmission \& Distribution, vol.4, no.1, pp. 94-103, 2010.

[15] K. Mazlumi, H. A. Abyaneh, S. Sadeghi, and S. Geramian, "Determination of Optimal pmu Placement for Fault-Location Observability," in 2008 Third International Conference on Electric Utility Deregulation and Restructuring and Power Technologies. IEEE, 2008, pp. 1938- 1942.

[16] C. Y. Evrenosoglu and A. Abur, "Travelling Wave Based Fault Location for Teed Circuits," IEEE Transactions on Power Delivery, vol. 20, no. 2, pp. 1115-1121, 2005.

[17] J. Izykowski, E. Rosolowski, M. M. Saha, M. Fulczyk, and P. Balcerek, "A Fault-Location Method for Application with Current Differential Relays of Three-Terminal Lines," IEEE Transactions on Power Delivery, vol. 22, no. 4, pp. 2099-2107, 2007.

[18] K.-P. Lien, C.-W. Liu, C.-S. Yu, and J.-A. Jiang, "Transmission Network Fault Location Observability with Minimal pmu Placement," IEEE Transactions on Power Delivery, vol. 21, no. 3, pp. 1128-1136, 2006.

[19] V. Terzija, Z. M. Radojevi'c, and G. Preston, "Flexible Synchronized Measurement Technology-based Fault Locator," IEEE Transactions on Smart Grid, vol. 6, no. 2, pp. 866-873, 2014.

[20] T. P. Hinge and S. S. Dambhare, "Secure Phase Comparison Schemes for Transmission-line Protection Using Synchrophasors,” IEEE Transactions on Power Delivery, vol. 30, no. 4, pp. 2045-2054, 2015.

[21] S. A. Soman, “A Web Course on power system protection," NPTEL. 